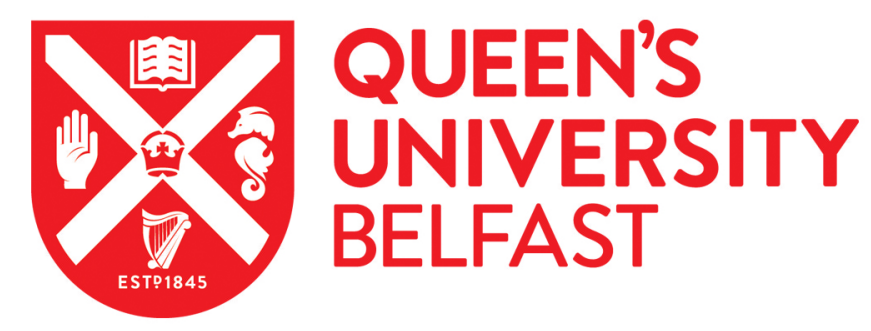

\title{
Compact FSS absorber design using resistively loaded quadruple hexagonal loops for bandwidth enhancement
}

Zabri, S. N., Cahill, R., \& Schuchinsky, A. (2015). Compact FSS absorber design using resistively loaded quadruple hexagonal loops for bandwidth enhancement. IET Electronic Letters, 51(2), 162-164. https://doi.org/10.1049/el.2014.3866

Published in:

IET Electronic Letters

Document Version:

Peer reviewed version

Queen's University Belfast - Research Portal:

Link to publication record in Queen's University Belfast Research Portal

Publisher rights

This paper is a postprint of a paper submitted to and accepted for publication in Electronics Letters and is subject to Institution of Engineering and Technology Copyright. The copy of record is available at IET Digital Library.

\section{General rights}

Copyright for the publications made accessible via the Queen's University Belfast Research Portal is retained by the author(s) and / or other copyright owners and it is a condition of accessing these publications that users recognise and abide by the legal requirements associated with these rights.

Take down policy

The Research Portal is Queen's institutional repository that provides access to Queen's research output. Every effort has been made to ensure that content in the Research Portal does not infringe any person's rights, or applicable UK laws. If you discover content in the Research Portal that you believe breaches copyright or violates any law, please contact openaccess@qub.ac.uk. 


\section{Compact FSS absorber design using resistively loaded quadruple hexagonal loops for bandwidth enhancement}

\author{
S. N. Zabri, R. Cahill, and A. Schuchinsky
}

\begin{abstract}
This letter presents the design of a thin microwave absorber which exhibits a $-10 \mathrm{~dB}$ reflectivity bandwidth of $108 \%$ at normal incidence and $16 \%$ for simultaneous suppression of TE and TM polarised waves over the angular range $0^{\circ}-45^{\circ}$. The structure consists of a $3 \mathrm{~mm}$ thick metal backed frequency selective surface (FSS) with four resistively loaded hexagonal loop elements in each unit cell. The surface resistivity and width of the loops are carefully chosen to maximise the bandwidth by merging the reflection nulls that are generated by the multi resonant absorber. Measurement and simulation results are in good agreement over the broad frequency range $7.8-24 \mathrm{GHz}$.
\end{abstract}

Introduction: Microwave absorbers based on resistively loaded high impedance surfaces [1] are an attractive option for providing radar cloaking where the main design drivers are weight and thickness. However the reflectivity bandwidth of this class of absorber is proportional to the structure thickness [2]-[6], which is determined by the gap between the FSS and ground plane. In [2] a $-10 \mathrm{~dB}$ reflectivity bandwidth of $109 \%$ was obtained from a $5 \mathrm{~mm}$ thick metal backed resistively loaded single square loop FSS array. This was designed to resonate at the two frequencies where the imaginary component of the FSS impedance is cancelled by the inductance and capacitance presented by the ground plane with gap widths of $\langle\lambda / 4$ and $>\lambda / 4$ at the lower and upper frequencies respectively. The FSS absorber studied in this paper is shown to give a similar bandwidth, however the ground plane spacing is $<\lambda / 4$ at all frequencies where the reflectivity is below - $10 \mathrm{~dB}$. Moreover because the structure is $40 \%$ thinner, the figure of merit (FOM), which is defined as the common (TE/TM) bandwidth divided by the physical thickness normalised to the centre working frequency, is significantly larger, 670 compared to 470 in [2]. For this arrangement, radar backscatter suppression occurs at four frequencies where the complex impedances of the individual hexagonal loops cancel the inductance which is presented by the ground plane. In [3], [5], [7]-[9] the simulated backscatter suppression for various resistively loaded thin FSS absorbers based on single and nested square loop elements has been reported, but only for normal or small incidence angle operation. The structure depicted in Fig. 1 which was studied in this paper, exhibits higher FOM values except for the arrangement reported in [7], where numerical results are presented for a FSS design with different surface resistances for the 5 individual nested elements in the range $4-1680 \Omega$ /square. In contrast, our methodology enables the use of the same surface resistance for all four hexagonal loops in the unit cell which significantly simplifies the construction and manufacture of the FSS. Bi-static measured results obtained for an absorber with an FSS that was fabricated by patterning a uniform thickness film of commercially available shielding paint [10] are shown to be in good agreement with numerical predictions for TE and TM waves incident at $0^{\circ}, 22.5^{\circ}$ and $45^{\circ}$.

Absorber Design and simulated performance: CST Microwave Studio EM simulator was employed to optimise the design, obtain the physical dimensions and compute the radar backscatter from the thin metal backed FSS absorber. The unit cell arrangement shown in Fig. 1, consists of four hexagonal loops printed on a $0.13 \mathrm{~mm}$ thick substrate with permittivity $\varepsilon_{\mathrm{r}}=2.2$ and loss tangent $\tan \delta=0.0009$ (Taconic TLY$5)$. The array elements are separated from the ground plane by a $3 \mathrm{~mm}$ thick lossless foam spacer with permittivity 1.05 (Rhoacell). A tightly packed hexagonal loop FSS exhibits a wide reflection bandwidth [11] and less sensitivity to incidence angle than most other commonly used array geometries. Moreover the slow frequency variation in impedance around resonance is a desirable feature for broadbanding this class of absorbers, given that maximum radar backscatter suppression occurs when the imaginary part of the FSS impedance is cancelled by the inductance presented by the ground plane. Total absorption of the incident waves is obtained when the surface resistance of the hexagon loops is chosen to give an impedance of $377 \Omega$ at the screen surface. The electromagnetic performance of the absorber was optimised for normal incidence using a three stage iterative design process:
(1) Resonances corresponding to the centre of the four absorption bands were excited at pre-determined frequencies $(6.5,12.2,18.5$ and $31 \mathrm{GHz})$ by adjusting the length of the individual copper hexagonal loops to obtain a reflection phase of $0^{\circ}$ at the centre of each band.

(2) The surface resistance of each loop was increased to reduce the magnitude of the four reflection nulls below $-10 \mathrm{~dB}$ and simultaneously merge these to broadband the absorber. Numerical predictions show that four different surface resistance values, one for each loop, are required to optimise the electromagnetic performance.

(3) By varying the conductor widths and gaps between the four individual hexagons in each unit cell, a modified FSS design with a similar performance as at step (2) was obtained using a single value of surface resistance $(27 \mathrm{ohm} / \mathrm{sq})$ for all four loops. Given that this design parameter is inversely proportional to the thickness of graphite and carbon based shielding paint [1], [2], construction of the absorber is made easier because the periodic array can be patterned on a resistive ink film of uniform thickness.

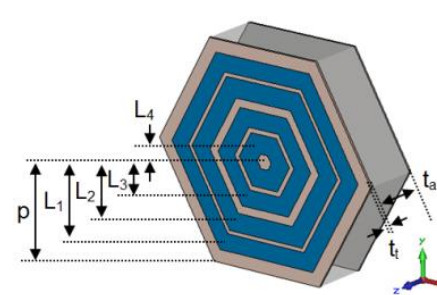

(a)

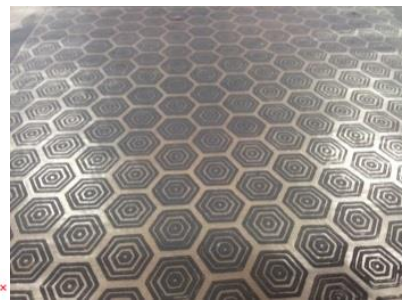

(b)
Fig. 1 (a) Schematic and dimensions of the FSS unit cell; $p=6.93 \mathrm{~mm}, \quad L_{1}=5.56 \mathrm{~mm}, \quad L_{2}=4.17 \mathrm{~mm}, \quad L_{3}=2.49 \mathrm{~mm}, \quad L_{4}=1.05 \mathrm{~mm}$, $w_{1}=1.1 \mathrm{~mm}, w_{2}=1.2 \mathrm{~mm}, w_{3}=1.1 \mathrm{~mm}, w_{4}=1.2 \mathrm{~mm}, R=27 \mathrm{ohm} / \mathrm{sq}, t_{a}=3 \mathrm{~mm}$, $t_{t}=0.13 \mathrm{~mm}$ (b) Photograph of 208 unit cell resistively loaded FSS

Fig. 2 (a) depicts the computed reflection loss for the absorber operating at normal incidence where the symmetry afforded by the element shape gives identical spectral responses in the TE and TM plane. The $-10 \mathrm{~dB}$ reflectivity bandwidth is predicted to be $108 \%$ (7.1- $24 \mathrm{GHz}$ ), and with a total structure thickness of $3.13 \mathrm{~mm}$ the FOM is 670 . This figure of merit is higher than most previously reported thin FSS absorbers working at normal incidence, and compares favourably with the 308 value for the classical $\lambda / 4$ thick Salisbury screen [12]. Angular sensitivity is an important consideration when the absorber is required to suppress radar backscatter over a range of angles. We have therefore investigated the performance of the structure when illuminated by TE and $\mathrm{TM}$ waves incident at $22.5^{\circ}$ and $45^{\circ}$. The results depicted in Fig. 2(b) and (c) show that there is an upward shift of the centre resonant frequency for TM polarised waves, whereas angular stability in conjunction with a reduction in the reflectivity levels and bandwidth are observed in the TE plane. For an absorber working between normal incidence and $22.5^{\circ}$, the common reflectivity bandwidth and FOM in the TE and TM planes is predicted to be $99.8 \%(\mathrm{FOM}=622)$ and $98.1 \%$ $(\mathrm{FOM}=585)$, respectively. If the angular range of the incident waves is increased up to $45^{\circ}$ these values reduce to $25.1 \%$ ( $\mathrm{FOM}=142$ ) and $36.6 \%(\mathrm{FOM}=174)$. The numerical results also show that the $3 \mathrm{~mm}$ thick absorber suppresses radar backscatter by at least $90 \%$ between $16.4 \mathrm{GHz}$ and $19.18 \mathrm{GHz}(16 \%)$, when used for dual polarisation cloaking from $0^{\circ}$ to $45^{\circ}$ incidence.

Fabrication and measured Results: A $15 \times 15 \mathrm{~cm}^{2}$ metal backed $3 \mathrm{~mm}$ thick FSS absorber was fabricated and measured to validate the design methodology and numerical simulations presented in the previous section. The FSS was composed of a doubly periodic array with $13 \times 16$ unit cells printed on a $0.13 \mathrm{~mm}$ thick Taconic TLY-5 microwave laminate $\left(\varepsilon_{\mathrm{r}}=2.2\right.$ and $\left.\tan \delta=0.0009\right)$ and bonded to a $3 \mathrm{~mm}$ thick Rhoacell spacer backed by an aluminium plate. Y Shield HSF-74 [10] electro conductive shielding paint was used to form the elements on the surface of the substrate by transferring the array pattern using a Linoleum sheet template. A photograph of the 208 unit cell sheet is shown in Fig. 1(b). Y Shield HSF-74 is a graphite and carbon black based material which is reinforced with long conductive fibres providing up to $36 \mathrm{~dB}$ signal attenuation at frequencies up to $18 \mathrm{GHz}$ 
when applied at a coverage rate of $7.5 \mathrm{~m}^{2} / 1$ [10]. Physical measurements of the average paint film thickness were made using a Tencor AlphaStep 200 Profilometer and the inverse relationship between surface resistance and thickness shown in Fig. 6 of reference [1], was used to obtain an average experimental value of $35 \mathrm{ohm} / \mathrm{sq}$ for the $43 \mu \mathrm{m}$ thick loops. Time-gated bi-static reflection measurements were made in an anechoic chamber relative to a $15 \times 15 \mathrm{~cm}^{2}$ metal plate that was placed $30 \mathrm{~cm}^{2}$ distance from the apertures of three pairs of standard gain horns which cover the frequency range $7-27 \mathrm{GHz}$. The experimental reflectivity plots for the FSS absorber at $0^{\circ}, 22.5^{\circ}$ and $45^{\circ}$ incidence shown in Fig. 2 compare favourably with the simulations that were based on the nominal design dimensions of the FSS and a modelled surface resistance value of $27 \mathrm{ohm} / \mathrm{sq}$. The measured $-10 \mathrm{~dB}$ reflectivity bandwidth is $102 \%$ at normal incidence, and for TE(TM) incidence $95.1 \%(83.2 \%)$ working from $0^{\circ}$ to $22.5^{\circ}$, and $54 \%(50 \%)$ in the range $0^{\circ}$ to $45^{\circ}$. These values correspond more closely to simulations obtained for a FSS constructed with elements that exhibit a surface resistance of $35 \mathrm{ohms} / \mathrm{sq}$ (not plotted in Fig. 2 for brevity).

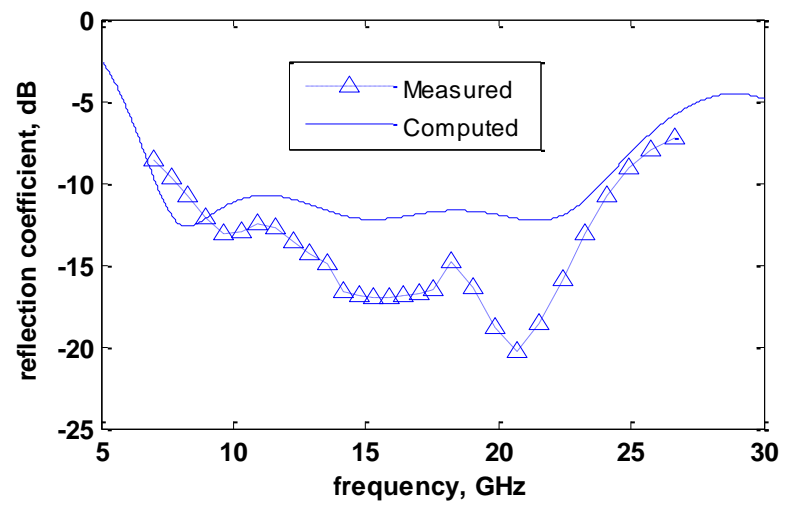

a)

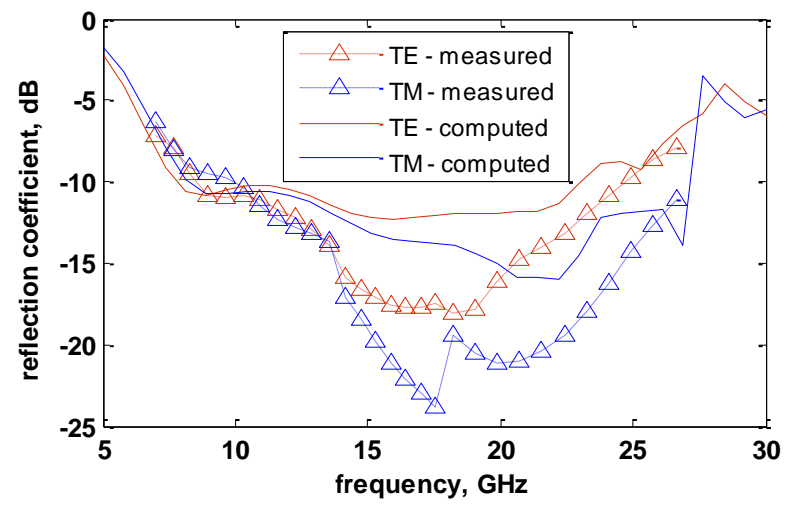

b)

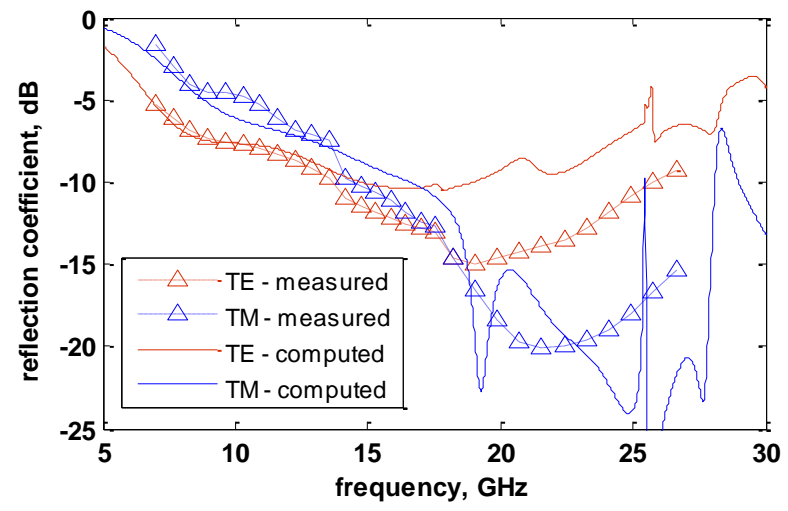

c)

Fig. 2 Simulated and measured reflectivity plots (a) normal incidence, (b) $22.5^{\circ}$ incidence, (c) $45^{\circ}$ incidence; (b) \& (c) show grating lobe responses which appear at oblique incidence.
Conclusion: Numerical results have been employed to show that a 3 mm thick FSS based microwave absorber can be designed to supress microwave radiation at normal incidence over a bandwidth of $108 \%$ centred at $15.6 \mathrm{GHz}$, and $16 \%$ when exposed to both TE and TM waves, incident over an angular range $0^{\circ}$ to $45^{\circ}$. An important outcome from this work is the demonstration of a new design methodology which simplifies the fabrication of the absorber by making the surface resistance and hence ink thickness the same for all the four nested loops in the FSS unit cell. The simulated performance was validated by measuring the radar backscatter from a grounded FSS composed of a patterned layer of high frequency paint which is normally employed to provide electromagnetic shielding of buildings [10].

Acknowledgments: S. N. Zabri is supported by a research scholarship from University Teknikal Malaysia Melaka, Malaysia.

S. N. Zabri, R. Cahill and A. Schuchinsky (The Institute of Electronics, Communications and Information Technology (ECIT), Queen's University Belfast, Northern Ireland Science Park, Queen's Road, Queen's Island, Belfast BT3 9DT, Northern Ireland, UK)

E-mail: r.cahill@qub.ac.uk

\section{References}

1 Zabri, N., Cahill, R., Schuchinsky, A.: 'Polarisation independent resistively loaded frequency selective surface absorber with optimum oblique incidence performance', IET Microwaves, Antennas Propag., doi:10.1049/iet-map.2014.0124, to be published Nov. 2014

2 Costa, F., Monorchio, A., Manara, G.: 'Analysis and design of ultra thin electromagnetic absorbers comprising resistively loaded high impedance surfaces', IEEE Trans. Antennas Propag., 2010, 58, (5), pp. 1551-1558, doi: 10.1109/TAP.2010.2044329

3 Shang, Y., Shen, Z., Xiao, S.: 'On the design of single-layer circuit analog absorber using double-square-loop array', IEEE Trans. Antennas Propag., 2013, 61, (12), pp. 6022-6029, doi: 10.1109/TAP.2013.2280836

4 Rui Zhang, G., Heng Zhou, P., Bin Zhang, H., Bo Zhang, L., Liang Xie, J., Jiang Deng, L.: 'Analysis and design of triple-band high-impedance surface absorber with periodic diversified impedance', J. Appl. Phys., 2013, 114, (16), pp. 164103, doi: 10.1063/1.4826265

5 Yang, J., Shen, Z:: 'A Thin and broadband absorber using doublesquare loops', Antennas Wirel. Propag. Lett., 2007, 6, (11), pp. 388391, doi: 10.1109/LAWP.2007.903496

6 Peng, L., Ke, L., Hou , X.: 'Design of an absorber with high impedance surfaces', in 9th International Symposium on Antennas, Propagation and EM Theory, Guangzhou, December 2010, pp. 1097-1100, doi: 10.1109/ISAPE. 2010.5696668

7 Martinez, I., Panaretos, A. H., Werner, D. H., Oliveri, G., Massa, A.: 'Ultra-thin reconfigurable electromagnetic metasurface absorbers', 7th European Conference on Antennas and Propagation (EuCAP), Gothenburg, April 2013, pp. 1784-1788

8 Li, M., Xiao, S., Bai, Y.-Y., Wang, B.-Z.: 'An Ultrathin and broadband radar absorber using resistive FSS', IEEE Antennas Wirel. Propag. Lett., 2012, 11, pp. 748-751, doi: 10.1109/LAWP.2012.2206361

9 Panaretos, A. H., Martinez, I., Werner, D. H.: 'Ultra-thin wideband absorbers comprised of Frequency Selective Surfaces with concentric square loop elements', IEEE Antennas and Propagation Society International Symposium (APSURSI), Orlando, Florida, July 2013, pp. 478-479, doi: 10.1109/APS.2013.6710900

10 'Y-SHIELD EMR Protection', http://www.yshield.com/, accessed January 2013

11 Bing-yuan, L., Zheng-hui, X., Wei-ming, L., Wu, R.: 'Ultra-wideband frequency selective surface at $\mathrm{K}$ and $\mathrm{Ka}$ band', IEEE International Conference on Microwave Technology \& Computational Electromagnetics, Qingdao, August 2013, pp. 55-57, doi: 10.1109/ICMTCE.2013.6812480

12 Che Seman, F., Cahill, R., Fusco, V. F.: 'Low profile Salisbury screen radar absorber with high impedance ground plane', Electron. Lett., 2009, 45, (1), pp. 10-12, doi: 10.1049/el:20093098 